\title{
A longitudinal inquiry into directionality of effects between coping and information needs in hypertensive patients
}

This article was published in the following Dove Press journal:

Psychology Research and Behavior Management

\author{
Andrea Greco' \\ Erika Rosa Cappelletti ${ }^{2}$ \\ Koen Luyckx ${ }^{3,4}$ \\ Marco D'Addario ${ }^{5}$ \\ Cristina Giannattasio $0^{6,7}$ \\ Patrizia Steca ${ }^{5}$ \\ 'Department of Human and Social \\ Sciences, University of Bergamo, \\ Bergamo, Italy; ${ }^{2}$ Social healthcare \\ Academy, Polis Lombardia, Regional \\ Institute for Policy Support, Milan, \\ Italy; ${ }^{3}$ Faculty of Psychology and \\ Educational Sciences, KU Leuven, \\ Leuven, Belgium; ${ }^{4}$ UNIBS, University \\ of the Free State, Bloemfontein, South \\ Africa; ${ }^{5}$ Department of Psychology, \\ University of Milan-Bicocca, Milan, \\ Italy; ${ }^{6}$ Department of Cardiology, \\ ASST GOM Niguarda Ca' Granda, \\ Milan, Italy; ${ }^{7}$ Medicine and Surgery \\ Department, Bicocca University, Milan, \\ Italy
}

Purpose: It is well recognized that effective health communication is associated with better adherence to medical prescriptions, behavioral changes, and enhanced perception of control over the disease. However, there is limited knowledge about the variables on which to tailor health messages. This study examined whether coping strategies were related to information needs over time in a sample of patients with hypertension.

Patients and methods: A three-wave longitudinal design was used to examine the potential reciprocal relationships among variables. The sample included 271 patients (43.5\% women) affected by essential arterial hypertension with a mean age of 54.66 years (SD $=10.74$ years; range 30-78 years). Data on patients' demographic characteristics, coping strategies, and information needs were collected three times over 12 months. To test the directionality of the relationships linking coping to information needs, cross-lagged path analyses were applied in a structural equation modeling approach.

Results: Active coping was related to a greater need for information regarding behavioral habits; avoidance coping was negatively associated with the need for information regarding daily life activities, while passive coping showed a positive relationship with this need. Moreover, results sustained the hypothesis that the relationship between coping and information needs was bi-directional. In fact, greater need for information about the disease and its pharmacological treatment was related to greater adoption of active coping strategies. The need for information about risk and complications was associated with the coping strategy related to alcohol use.

Conclusion: These results provide important suggestions for implementing more effective intervention programs aimed at fostering patients' self-care abilities. As it was possible to modify coping strategies, health care providers may consider measuring patients' strategies before the medical examination so they have time to refine the information they give to patients.

Keywords: coping strategies, health communications, chronic diseases, hypertension, intervention programs

\section{Introduction}

Hypertension is the main preventable risk factor for premature cardiovascular death worldwide. It affects $\sim 30 \%-45 \%$ of the general population, and its rate is increasing. ${ }^{1}$ Given the high prevalence and related morbidity of hypertension, high priority should be given to research aimed at increasing knowledge on its prevention and treatment. ${ }^{2}$ There is a growing body of literature which indicates that effective communication from health care providers to patients affected by chronic diseases is associated with better adherence to medical prescriptions, self-management behaviors, reduced psychological distress, and enhanced perceived control of the disease. ${ }^{3-5}$ This relationship has
Correspondence: Erika Rosa Cappelletti Social healthcare Academy, Polis Lombardia, Regional Institute for Policy Support, Via Taramelli I2 F, 20124, Milan, Italy

Email erikarosa.cappelletti@gmail.com 
been explained through the Information-Motivation-Strategy Model. According to this model, patients with chronic diseases need to profoundly change their unhealthy behaviors and habits (like smoking, poor diet, low level of physical activity, and alcohol consumption) and adhere to treatment in order to manage their condition. This means that patients must first know what should they do, then be appropriately motivated to engage in the necessary action, and, finally, have the resources to carry out that action. Any one or two of these elements are insufficient; all three are essential. ${ }^{6,7}$ In recent years, there has been increased emphasis on the importance of tailoring health messages to support patients' information processing and health behavioral changes. ${ }^{8-11}$ In particular, there has been growing interest in the concept of information needs, defined as a recognition of patients' knowledge of their disease and related aspects, in order to adequately satisfy their preferences in relation to the information that they want and to identify the variables that could affect this need for health information. Evidence suggests that patients regard all types of information as important, with a preference for the following domains: medication or pharmacological treatment, knowledge about the disease and cardiac anatomy and physiology, risk factors and complications related to the disease, impact of the disease on everyday life, behavioral habits to modify after the diagnosis, and how to manage stress caused by the disease. ${ }^{12-17}$ Furthermore, some reports have found associations between information needs and patients' sociodemographic characteristics. More highly educated patients have reported a lower need for medical information (eg, information on drugs and medicine) and a greater need for information on behavioral habits, while older patients have reported being less interested in information on how to manage disease-related stress. ${ }^{17,18}$ However, these results are inconsistent with others, and there is now greater acknowledgment that limiting considerations to sociodemographic aspects might result in a mismatch of patients' preferences and communication content. ${ }^{19,20}$ In addition to sociodemographic features, psychological factors closely related to individual health behaviors should be considered to better understand patients' information needs and tailor health messages to provide more effective communication. Among other psychological aspects, coping strategies may play a pivotal role.

Coping refers to a variety of strategies individuals use to manage their stress that are strictly related to the pursuit of individual goals. ${ }^{21,22}$ In the health context, it indicates the cognitive and behavioral efforts that an individual puts forth to manage the stressors that accompany the disease. Folkman and Lazarus ${ }^{23}$ distinguished between two main strategies: problem-focused strategies, which aim at solving and actively responding to stressful situations, and emotionfocused strategies, which aim at managing or reducing the feelings that are embedded within stressful situations. They also identified information seeking as one of the most common methods used to cope with a new, stressful event like a disease $;{ }^{24}$ thus, information needs may be largely connected to coping strategies in managing health. ${ }^{23,25-27}$

The aim of the present study was to contribute to the knowledge on how to tailor health information by providing insight into the level of reciprocal influences between health information needs and coping strategies in a cohort of patients with essential hypertension. As shown in Figure 1, a three-wave longitudinal design was adopted that uses three competing cross-lagged models to examine potential reciprocal relationships among the study variables. The models were tested to obtain a detailed view on the longitudinal dynamics between information needs and coping strategies. First, as represented in Panel A of Figure 1, the first model assumed that the strategies used by patients to cope with their disease were related to their need for information on different topics related to disease management. Second (Panel B of Figure 1), the model assumed that patients' need for health information was related to the way they would cope with stress due to the disease. Third, the integration of these two models gave rise to the reciprocal effects model, which assumed that information needs and coping strategies were part of a mutually reinforcing system over time (Panel C of Figure 1).

To explore reciprocal relationships, two preliminary hypotheses were tested. The first hypothesis was based on the results of studies that have concluded that information needs occur as a result of the individual's natural coping mechanism, whereby they seek out information in response to a problemfocused approach. ${ }^{28}$ It assumed that patients' strategies to cope with their hypertension would relate to their information needs. It was expected that the adoption of problem-focused strategies, such as active coping or searching for social support, would lead to an increased need for information on disease management, especially for domains more related to self-care behaviors, which require patients to be involved in their health care. It was also expected that patients who tended to apply emotion-focused coping, such as passive coping or avoidance, would be less interested in information related to disease management. The second hypothesis was based on the results reporting that patients who were interested in receiving information about their disease and its treatment showed better coping abilities at the diagnosis stage, as well as during and after treatment. ${ }^{29}$ Other benefits related to needed information 


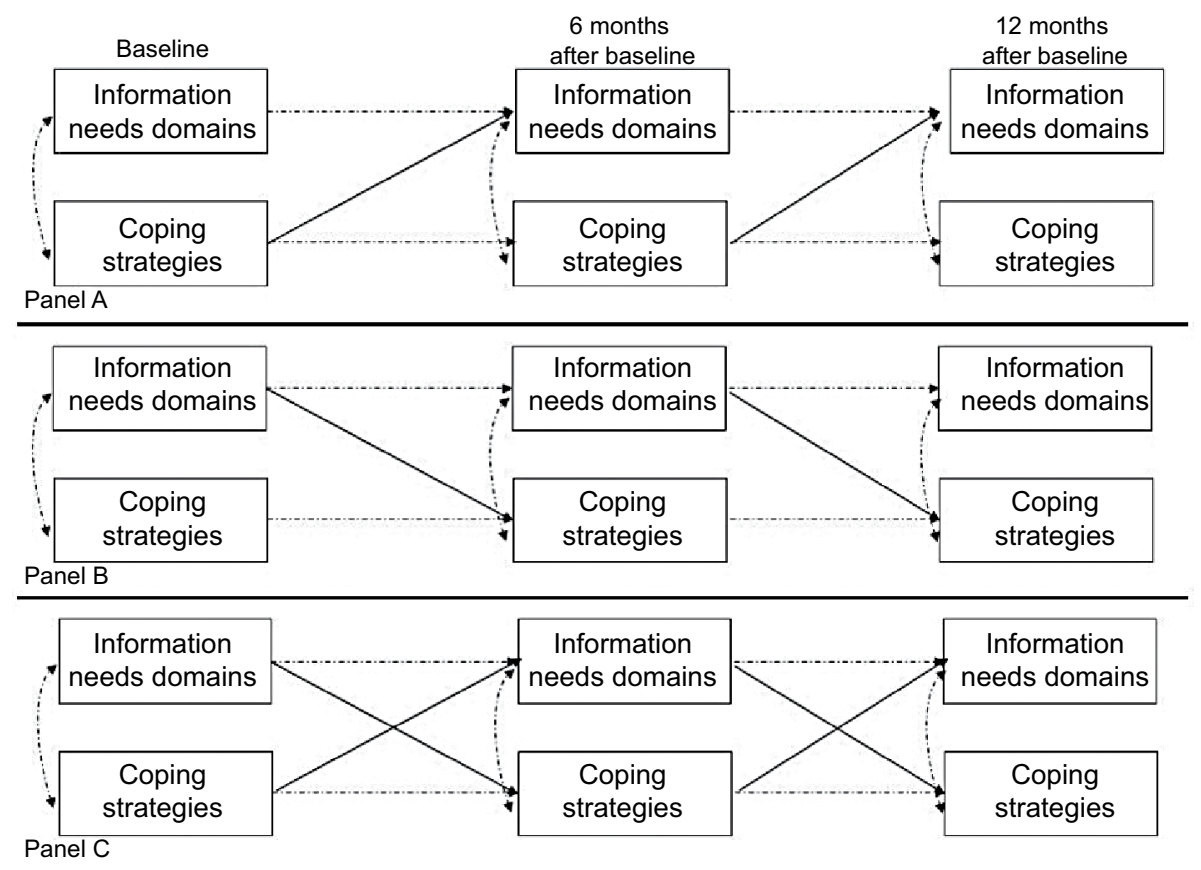

Figure I Conceptual model linking information needs domains and coping strategies.

Note: Panel A: a coping main-effects model; Panel B: an information needs main-effects model; Panel C: a reciprocal effect model.

were a greater capacity to learn about the treatment regimen and its possible complications and developing skills to help reduce them. ${ }^{30}$ Thus, it was expected that patients needing greater information at baseline would adopt more problemfocused coping in the following months, while those who are less interested in information at baseline would adopt more emotion-focused coping.

\section{Patients and methods Procedure and participants}

Patients with essential arterial hypertension who had been referred to the Clinica Medica (medical clinic) unit of a hospital in Northern Italy were recruited to participate in this study. Inclusion criteria were as follows:

Diagnosis of primary hypertension (SBP $\geq 140 \mathrm{mmHg}$ and/or $\mathrm{DBP} \geq 90 \mathrm{mmHg}$, patients already in pharmacological treatment, and/or patients for whom elevated blood pressure values had been diagnosed by mean arterial pressure 24 hours) $\geq 30$ years of age. Able to complete the study measures and interventions in Italian.

Exclusion criteria were as follows:

Diagnosis of secondary hypertension. Diagnosis of diseases with limited expected survival (such as cancer). Diagnosis of psychiatric disorders. Moderate-severe cognitive impairment.
Eligible patients received written information about the study and were required to sign a consent form in accordance with the Declaration of Helsinki.

Later, a physician collected clinical data on patient body mass index, waist circumference, blood pressure values, asymptomatic organ damage, and the presence of different risk factors for cardiovascular diseases (CVDs) including sex, age, smoking, dyslipidemia (total/high-density/lowdensity lipoprotein cholesterol, and triglycerides), obesity, abdominal obesity, and family history of premature CVD. Following the directives of the "European Guidelines for the Management of Arterial Hypertension," "31 a total cardiovascular risk index (TCRi) was calculated for each patient by adding together the body pressure category, the number of cardiovascular risk factors, and the presence of asymptomatic organ damage, diabetes mellitus, and symptomatic CVD or chronic kidney disease. This variable indicates patients' risk of cardiac complications due to hypertension. After the clinical examination, participants were asked to report general demographic and clinical information including their gender, age, marital and employment status, education, and household type. They were given an open-ended question on how many months/years it had been since they were diagnosed with hypertension ("How long ago were you diagnosed with hypertension by a health care provider?"). The responses that were reported in years were re-coded in months (ie, if a patient reported having a diagnosis of 
hypertension for 2 years, we converted the answer to 24 months). This variable, called "Time since the diagnosis of hypertension" varied from $<2$ months to $>30$ years. After the collection of demographics and clinical variables, self-report questionnaires evaluating demographic characteristics, coping strategies, and information needs were administered by a trained researcher. The questionnaires were also administered in two subsequent follow-ups: 6 months after baseline (t1) and 12 months after baseline (t2). This procedure was almost the same in all the follow-ups.

The study was approved by the Ethical Committees of the University of Milan-Bicocca and ASST Monza-San Gerardo Hospital.

\section{Materials \\ Coping}

How participants coped with their hypertension was investigated through a 14-item instrument by Norcini-Pala and Steca. ${ }^{32}$ This is a multidimensional inventory used to assess the different ways in which patients with hypertension generally respond to stress related to the illness; the items describe 14 different coping strategies: acceptance, active coping, behavioral disengagement, denial, emotional support, humor, instrumental support, planning, positive reframing, religion, self-blame, self-distraction, substance use, and venting. Patients were given the following instructions for completing the questionnaire before it was administered: "This questionnaire asks you to indicate what you generally do and feel when you experience stressful events related to hypertension. Obviously, different events bring out somewhat different responses, but think about what you usually do when you are under a lot of stress due to hypertension. Then respond to each of the following items by filling in one number on your answer sheet for each, using the response choices listed just below. Please try to respond to each item separately in your mind from each other item. Choose your answers thoughtfully, and make your answers as true FOR YOU as you can. Please answer every item. There are no 'right' or 'wrong' answers, so choose the most accurate answer for YOU - not what you think 'most people' would say or do. Indicate what YOU usually do when YOU experience hypertension-related issues." The answer scale ranged from never (1) to very often (4). Factor analyses highlighted seven coping strategies that included five latent factors and two individual items; these seven factors showed acceptable reliability and concurrent and discriminant validity. ${ }^{32,33}$

The five-factor model was tested through a confirmatory factor analysis (CFA). The two individual items that assess alcohol use and religious coping were not included in the latent model (CFA) and were treated as observed variables in later analyses. $\mathrm{Hu}$ and Bentler's guidelines ${ }^{34}$ for various fit indices were used to determine whether the expected model was plausible with the data: a good model yields a non-significant chi-squared statistic $\left(\chi^{2}\right)$, a root mean square error of approximation (RMSEA), and a standardized root mean square residual $(\mathrm{SRMR})<0.08$. Moreover, it would be desirable to additionally report the comparative fit index (CFI). The CFI compares the fit of the null model in which all covariances are fixed to zero to the fit of the current model. However, cases where the RMSEA of the null model is $<0.158$ render the CFI non-interpretable. ${ }^{35}$ We therefore examined the RMSEA of the null model and found RMSEA null $=0.149$. Therefore, we refrained from reporting the CFI or other incremental fit indices.

The goodness of fit and reliability coefficient confirmed the adequacy of the model $\left(\chi^{2}=90.904, d f=44, P=0.000\right.$, RMSEA $=0.063$, SRMR $=0.060)$.

The five latent factors were:

Active coping, assessed with two items (eg, "I've been taking action to try to make the situation better" - loadings were 0.788 and 0.545$)$, reflecting patients' attempts to actively confront stressors.

Seeking social support, assessed with two items (eg, "I've been searching for support from others" - loadings were 0.894 and 0.401 ), referring to patients' attempts to cope with stressors by seeking support from persons other than their doctors.

Passive coping, assessed with three items (eg, "I admitted I cannot deal with the situation and gave up attempting to cope with it" - loadings ranged from 0.528 to 0.451 ), referring to a lack of appropriate action taken against the stressors.

Reappraisal, assessed with three items (eg, "I've been trying to see it in a different light, to make it seem more positive" - loadings ranged from 0.532 to 0.441 ), reflecting patients' reinterpretations of the stressful events in a more positive light.

Avoidance, assessed with two items (eg, "I acted as if nothing had ever happened to me" - loadings were 0.859 and 0.631), reflecting patients' denial and disengagement when facing hypertension-related stressors.

In this study, the internal consistency of the five-factor solution was corroborated by the factor score determinacy coefficients, ${ }^{36}$ which provide a measure of internal factor consistency. Coefficients of 0.70 or better indicate stable 
factors. ${ }^{37}$ In fact, the factor score determinacy coefficients in this study were $0.84,0.90,0.74,0.77$, and 0.89 , respectively.

\section{Information needs}

Patients' information needs were investigated with two questions evaluating the need for further information in one of six domains related to CVD management. ${ }^{17}$ These domains included pharmacological treatment (information on the types of medicines to take, when to take them, and their possible interaction with other medicines), knowledge about the disease (information on the anatomical/functional nature connected to the disease), distress (information on how to manage stress and worries that might be generated by the change in life caused by the disease), daily life activities (information about daily life activities that can be carried out and which ones have to be modified), behavioral habits (information about the habits that can be continued and those that should be modified regarding smoking, diet, alcohol, and physical activity), and risk and complications (information about the risks related to the disease and possible complications). The first question was specifically designed to identify the amount of further information desired by the patients in these six domains ("Indicate how much information you would like to receive about the following topics connected to the management of your cardiovascular disorders"). The answer format was on a 5-point Likert scale ranging from 1 ("I want to know nothing about the topic") to 5 ("I want to know everything about it"). The second question asked patients to rate the importance of the six domains and to assign a value from 1 to 6 ("Now please rate the importance of the topics listed below; you must assign a value from one for the most important topic, to six for the least important one). To identify the information needs, a balanced index was calculated by multiplying the score on question 1 by the score on question 2. Before computing the balanced index, the score on question 2 was reversed (eg, if a patient scored " 1 " on a topic, this response was recoded as 6). The balanced index had a score ranging from 1 to 30 with higher scores indicating a higher need for that domain. This was calculated to control for patients' tendencies to judge all information as "very" or "extremely" important. In fact, as found in previous research studies, ${ }^{38,39}$ patients tend to report high scores when they are directly asked how much information they desire, and they may not consider whether that information is useful for their specific situation. The balanced index provided a more accurate score of need for information rather than a general judgment of importance attributed to the topics.

\section{Statistical analysis}

Correlations among information needs, coping strategies, and sociodemographic and clinical variables were conducted to identify the variables that needed to be controlled in the models.

As shown in Figure 1, to examine the reciprocal influences between information needs and coping strategies, three competing cross-lagged models were tested and compared to obtain a detailed view on the longitudinal dynamics between information needs and coping strategies: 1) a coping strategies main-effects model, 2) an information needs main-effects model, and 3) a reciprocal effects model. First, the coping strategies main-effects model assumed that the strategies used by patients to cope with their disease were related to their need for information on different topics related to disease management. Second, the information needs main-effects model assumed that patients' need for health information had a relationship with the way they would cope with stress due to the disease. Finally, the integration of both these main-effects models gave rise to the third, the reciprocal effects model, which assumed that information needs and coping strategies were part of a mutually reinforcing system across time. The cross-lagged path analyses were applied from a structural equation modeling approach using Mplus software Version 7.0. ${ }^{36}$ The approach included all synchronous or within time associations and all autoregressive paths between adjacent measurement times. ${ }^{40}$ Moreover, as suggested by Cole and Maxwell and by Reichardt, ${ }^{41,42}$ all lagged effects among the variables were included because omission of a subset of paths may bias the estimates of the remaining paths. Finally, as suggested by Bollen ${ }^{43}$ in relation to the use of covariates, clinical and sociodemographic variables were controlled for by estimating paths to each of the constructs in the model.

To evaluate the different models, standard model fit indices were used. ${ }^{44}$ The $\chi^{2}$ index should be as small as possible. The RMSEA should be $<0.08$ (preferably 0.06) and the CFI should exceed 0.90 (preferably 0.95). Because several variables were not normally distributed, a robust chi-squared statistic and standard errors $(\mathrm{T} 2 *)^{45}$ were used, as implemented in Mplus with the MLR command.

Finally, cross-lagged analysis proceeded in two steps. First, all paths included in the model were freely estimated. Second, all the autoregressive paths between the adjacent measurement and the significant cross-lagged paths were constrained to be equal across the two time intervals (the path was made equal across Baseline-t1 and $\mathrm{t} 1 \mathrm{-t} 2$ ) resulting 
in a more parsimonious model. The Satorra-Bentler scaled chi-squared difference test (SBS- $\left.\chi^{2}\right),{ }^{46}$ which adjusts for the scaling correction factor used in the MLR estimation, ${ }^{47}$ and the $\Delta$ CFI, which should be $\leq 0.01$, were used for model comparisons.

\section{Missing data}

Participants with completed data were compared to those without using Little's missing completely at random test. ${ }^{48}$ The results indicated no significant difference, $\chi^{2}$ (312) $=313.57$, ns. Accordingly, the full information maximum likelihood procedure provided in Mplus 7.0 ${ }^{36}$ was applied, and all available information, including information from participants with missing data, was used to estimate the model parameters. ${ }^{49}$

\section{Results \\ Participants}

As shown in Figure 2, 314 patients with hypertension were invited to participate in the study, 35 of whom refused. Of the participating patients, five had secondary hypertension, two were being treated by a psychiatrist, and one moved away after the clinical assessment. Overall, 271 patients filled out the questionnaires at baseline; 25 patients declined to participate at $t 1$, for an attrition rate of $9.4 \%$, and 17 refused to participate at $\mathrm{t} 2$, for an attrition rate of $7 \%$. One patient died due to causes not directly related to hypertension before $t 2$. Patients who refused to participate at $\mathrm{t} 1$ and $\mathrm{t} 2$ did not differ from the final group with respect to sociodemographic variables, coping strategies, or needs for information as evaluated at baseline. Patients were included in the final study sample if they participated in at least one of the three measurement waves.

Hence, the study sample included 271 participants, out of which 118 were women (43.5\%). The mean age of the participants was 54.66 years $(\mathrm{SD}=10.74$ years; range $30-80$ years); $46.5 \%$ of the patients had graduated from secondary school, and the majority were still employed (54.7\%) and married (77.1\%). With respect to the clinical data, $42.15 \%$ of the sample had a family history of CVD, $32.7 \%$ presented dyslipidemia, $18.8 \%$ were obese, and $8.5 \%$ had diabetes. Additionally, 4.5\% had had prior cardiac events, and $1.3 \%$ had nephropathy. On average, patients had a diagnosis of hypertension for $\sim 9$ years ( $\mathrm{SD}=8.58$ years). A summary of participants' characteristics is reported in Table 1.

\section{Preliminary correlational analyses}

The cross-lagged models were controlled for patient demographic and clinical characteristics with moderate correla-

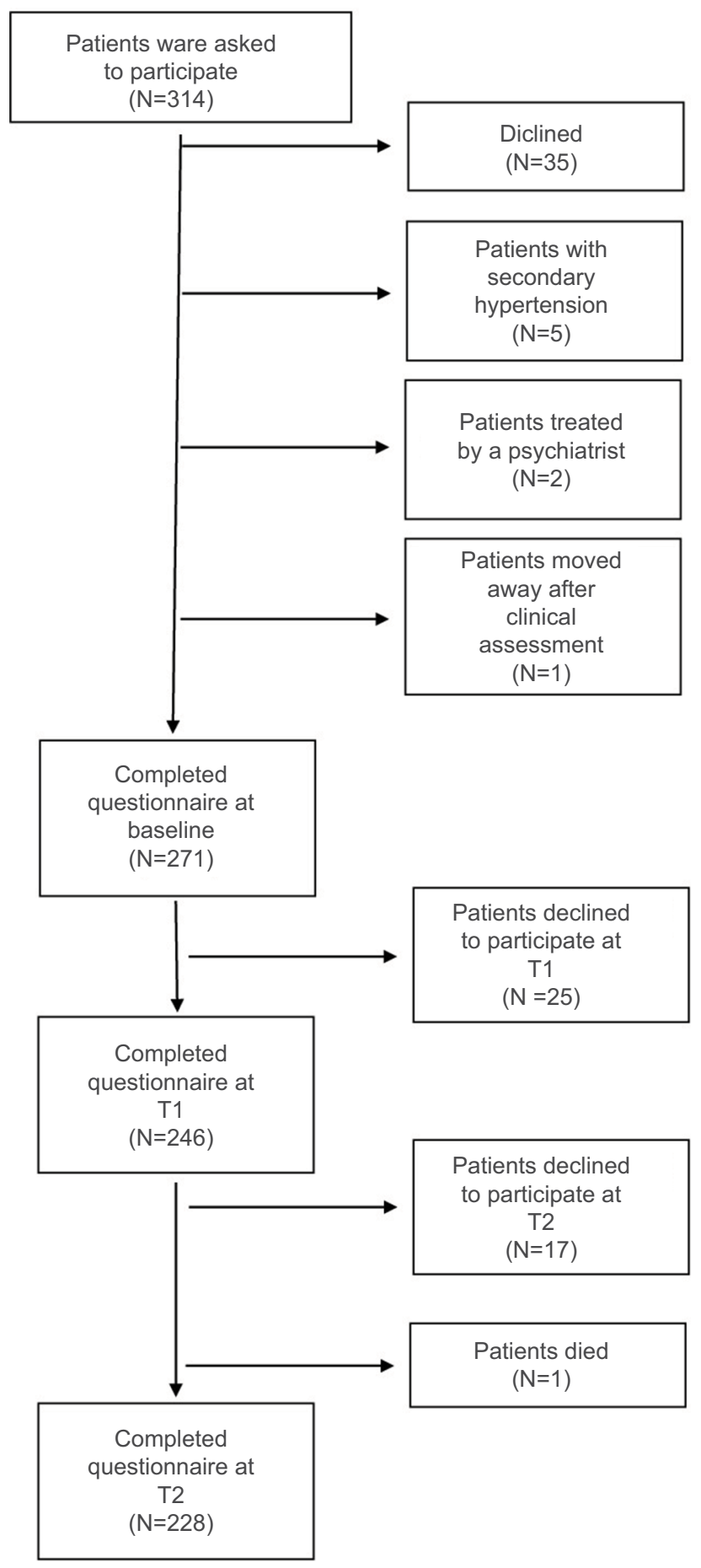

Figure 2 Overview of participating patients.

tion coefficients. Correlations were considered moderate if $>|0.20|$. The patients' background characteristics that met this criterion were age, gender, education, and TCRi (Table 2).

Age was negatively related to seeking social support and reappraisal and positively related to passive coping strategies. Older patients showed a lower tendency to rely on other 
Table I Characteristics of the study sample $(\mathrm{N}=27 \mathrm{I})$

\begin{tabular}{|c|c|c|c|}
\hline \multicolumn{2}{|l|}{ Sociodemographic variables } & \multicolumn{2}{|l|}{ Clinical } \\
\hline & Mean \pm SD & & Mean \pm SD \\
\hline Age, years & $54.66 \pm 10.74$ & Body mass index, $\mathrm{kg} / \mathrm{m}^{2}$ & $26.74 \pm 3.99$ \\
\hline Gender & n (\%) & Waist circumference, $\mathrm{cm}$ & $92.64 \pm 12.34$ \\
\hline Female & $118(43.5)$ & Total cholesterol, mg/dL & $200.6 \pm 34.11$ \\
\hline Male & $153(56.5)$ & Glucose, $\mathrm{mg} / \mathrm{dL}$ & $94.70 \pm 20.42$ \\
\hline Education & & Risk factors & n (\%) \\
\hline$<$ High School diploma & $88(32.5)$ & Dyslipidemia & $73(32.7)$ \\
\hline HS diploma & $126(46.5)$ & Smoking history & 37 (14.9) \\
\hline >HS diploma & $57(21)$ & Diabetes & $19(8.5)$ \\
\hline Marital status & & Obesity & $42(18.8)$ \\
\hline Married & $209(77.1)$ & Family history ${ }^{\mathrm{a}}$ & $94(42.1)$ \\
\hline Not married (also widowed/divorced) & $62(22.9)$ & Nephropathy & $3(1.3)$ \\
\hline Employment & & Prior cardiac events & $10(4.5)$ \\
\hline Employed & $148(54.7)$ & Menopause & $39(20.1)$ \\
\hline Retired & $71(26.2)$ & Blood pressure value, $\mathrm{mmHg}$ & Mean \pm SD \\
\hline Unemployed & $16(5.9)$ & Systolic & $134.25 \pm 17.02$ \\
\hline Housewife & $21(7.7)$ & Diastolic & $82.59 \pm 10.24$ \\
\hline Retired with some work activities & $15(5.5)$ & & \\
\hline
\end{tabular}

Note: ${ }^{a}$ Family history of premature hypertension and/or premature cardiovascular disease.

people or to reframe the situation when facing hypertension, but rather reported acting as if the disease had not occurred. Regarding gender, female patients reported relying more on religion than male patients. Education was negatively related to religion and to the need for information on the pathology. Less educated patients reported searching for comfort in their religion and desiring more information on what hypertension is. Finally, the TCRi was negatively related to the need for information about behavioral habits. Patients with a higher risk of developing cardiac complications of hypertension desired less information on lifestyle.

No significant correlations arose between the need for information or coping strategies and the variable related to "Time since the diagnosis of hypertension".

\section{Cross-lagged associations and stability coefficients}

The baseline model including all synchronous relations and all stability coefficients (including auto-regression coefficients between $\mathrm{t} 0-\mathrm{t} 1, \mathrm{t} 1-\mathrm{t} 2$, and $\mathrm{t} 0-\mathrm{t} 2)$ was estimated and provided an adequate fit to the data $\left(\chi^{2}[474]=609.99\right.$ $[P=0.000]$, RMSEA $=0.033, \mathrm{CFI}=0.953)$.

Next, in relation to the first hypothesis, the coping strategies main-effects model was estimated, which exhibited a good fit with the data $\left(\chi^{2}[306]=413.70[P=0.000]\right.$, RMSEA $=0.036$, CFI $=0.965)$. Furthermore, constraining all cross-lagged coefficients from coping to information needs as equal over time provided no worse fit to the data $\left(\chi^{2}[390]=503.41[P=0.000], \mathrm{RMSEA}=0.033, \mathrm{CFI}=0.963\right)$.
Invariance tests indicated that the more parsimonious invariant model fit the data equally well $\left(\Delta \mathrm{SBS}-\chi^{2}[84]=89.71\right.$, $P>0.05 ; \Delta \mathrm{CFI}=-0.002)$. Consequently, the constrained model was selected as the final coping strategies maineffects model. Four of the paths were significant: active coping strategies positively predicted information needs for behavioral habits; passive coping strategies positively predicted information needs about daily life activities; religion positively predicted information needs for risk and complications related to the disease; and avoidance coping negatively predicted information needs for daily life activities. All these significant paths emerged both from baseline to $\mathrm{t} 1$ and from $\mathrm{t} 1$ to $\mathrm{t} 2$.

In relation to the second hypothesis, the information needs main-effect model, including all lagged effects, had a good fit to the data $\left(\chi^{2}[330]=412.33[P=0.000], \operatorname{RMSEA}=0.030\right.$, $\mathrm{CFI}=0.973$ ). Furthermore, constraining all cross-lagged coefficients from information needs to coping as equal over time $\left(\chi^{2}[402]=504.47[P=0.000]\right.$, RMSEA $=0.031$, CFI $=0.967$ ) provided no worse fit to the data. The invariance tests indicated that the more parsimonious invariant model fit the data equally well $\left(\Delta \mathrm{SBS}-\chi^{2}[72]=92.14[P=0.06]\right.$, $\Delta \mathrm{CFI}=-0.006)$. Consequently, the constrained model was selected as the final information needs main-effects model. Three of the paths were significant: the need for information about pharmacological treatment and knowledge about the disease positively predicted active coping strategies, while information needs on risk and complications positively predicted alcohol use. 


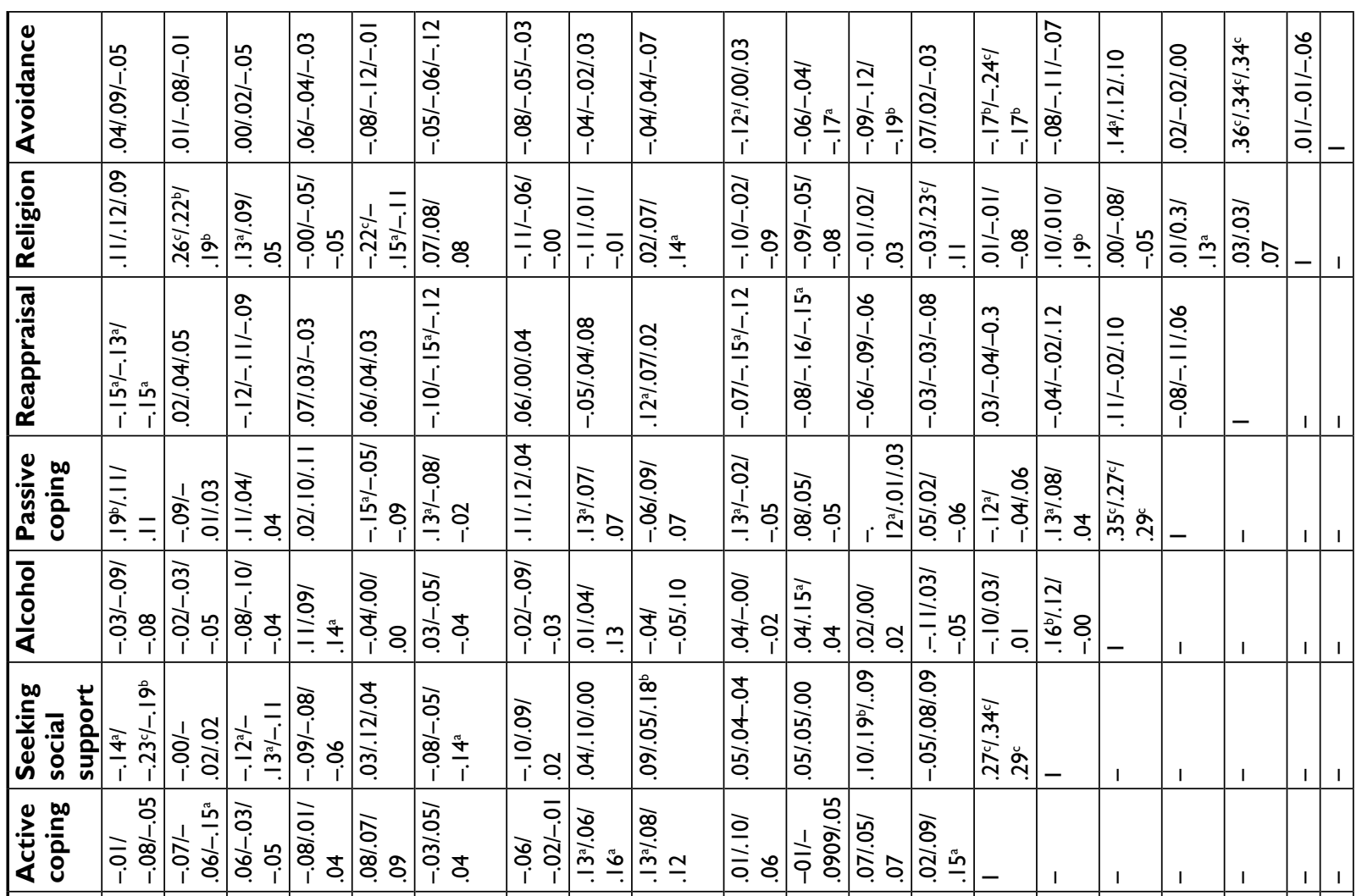

\begin{tabular}{|c|c|c|c|c|c|c|c|c|c|c|c|c|c|c|c|c|c|c|c|}
\hline 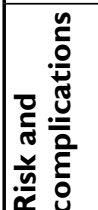 & 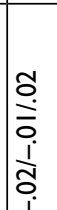 & 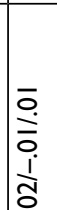 & 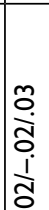 & 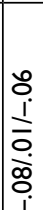 & $\begin{array}{l}\infty \\
\frac{1}{2} \\
\frac{1}{1} \\
\frac{1}{1}\end{array}$ & 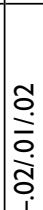 & 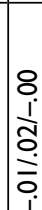 & 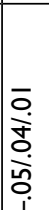 & 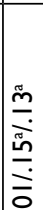 & 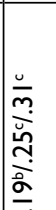 & 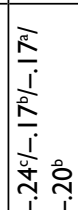 & 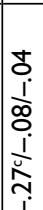 & 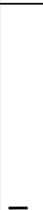 & & 1 & 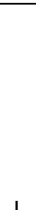 & 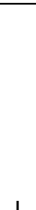 & 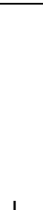 & \\
\hline & & & 0 & & 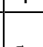 & $m$ & 8 & & $\delta$ & to & & & & & & & & & \\
\hline
\end{tabular}

\begin{tabular}{|c|c|c|c|c|c|c|c|c|c|c|c|}
\hline 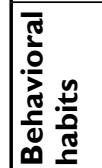 & $\begin{array}{l}\sigma \\
0 \\
\frac{1}{\lambda} \\
0 \\
i \\
1\end{array}$ & 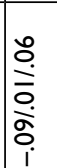 & 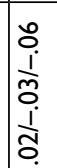 & 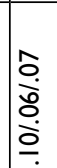 & 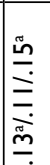 & $\begin{array}{l}0 \\
i \\
\frac{1}{y} \\
0 \\
i \\
0\end{array}$ & 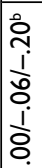 & 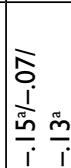 & $\frac{0}{0}$ & 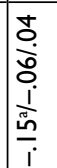 & 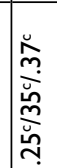 \\
\hline
\end{tabular}

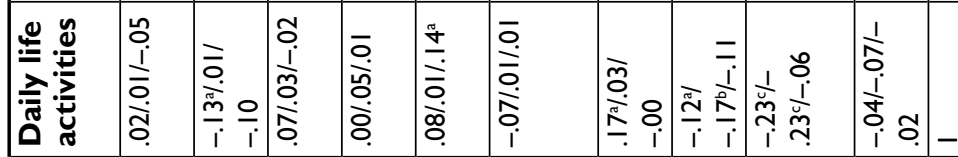

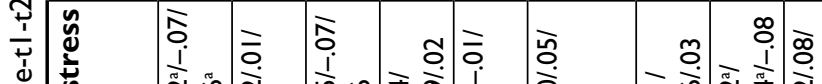

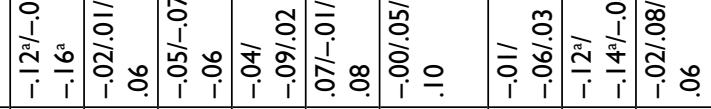

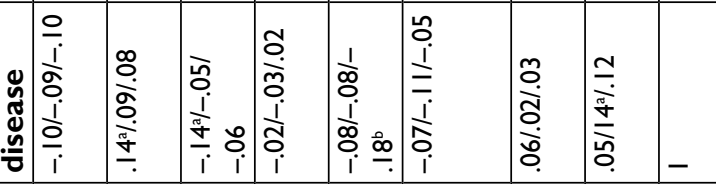

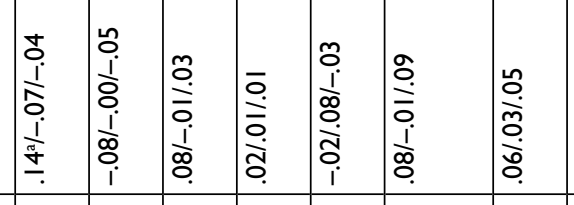

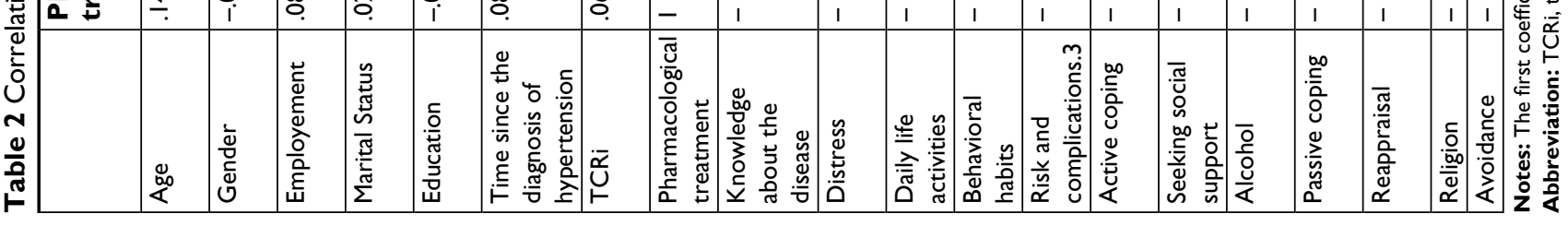


Finally, the reciprocal influences between information needs and coping strategies were tested combining both models; it gave rise to the reciprocal model, in which all the significant paths, four from the coping strategies main-effects model, and three from the information needs main-effects model, were combined. The seven aforementioned significant cross-lagged paths remained significant $\left(\chi^{2}[440]=449.97\right.$ $[P=0.03]$, RMSEA $=0.022$, CFI $=0.98)$. As in the other cases, constraining all cross-lagged coefficients as equal over time $\left(\chi^{2}[457]=514.39[P=0.32]\right.$, RMSEA $=0.022$, CFI $=0.98)$ provided no worse fit to the data, and invariance tests indicated that the more parsimonious invariant model fit the data equally well $\left(\Delta \mathrm{SBS}-\chi^{2}[17]=14.43[P=0.636], \Delta \mathrm{CFI}\right.$ $\Rightarrow>0.01$ ). Consequently, the constrained model was selected as the final model. Figure 3 presents a graphic depiction of the reciprocal effect model, which was the model sustained by the data. For reasons of clarity, all synchronous associations and stability coefficients are omitted from the figure. None of the models showed significant relationships between clinical or sociodemographic variables and coping strategies or information needs. Nevertheless, we must say that we did perform the sensitivity analysis, and despite the lost sample power, we did confirm that the results followed a similar trend and that the findings were generally robust. An exception to this is the path between religious coping strategy and risk and complications, which changed substantially becoming nonsignificant.

\section{Discussion}

The aim of the present study was to explore the reciprocal relationships between coping strategies and information needs over time in patients affected by essential hypertension using cross-lagged path analyses.

In order to identify the variables that needed to be controlled in the models, correlations among information needs, coping strategies, and sociodemographic and clinical variables were conducted. Multiple correlations were found. In particular, age was negatively related to problem-focused strategies and positively related to emotion-focused strategies. This result is consistent with previous research on the relationship between age and coping strategies that found that younger adults were generally more likely to use problem-

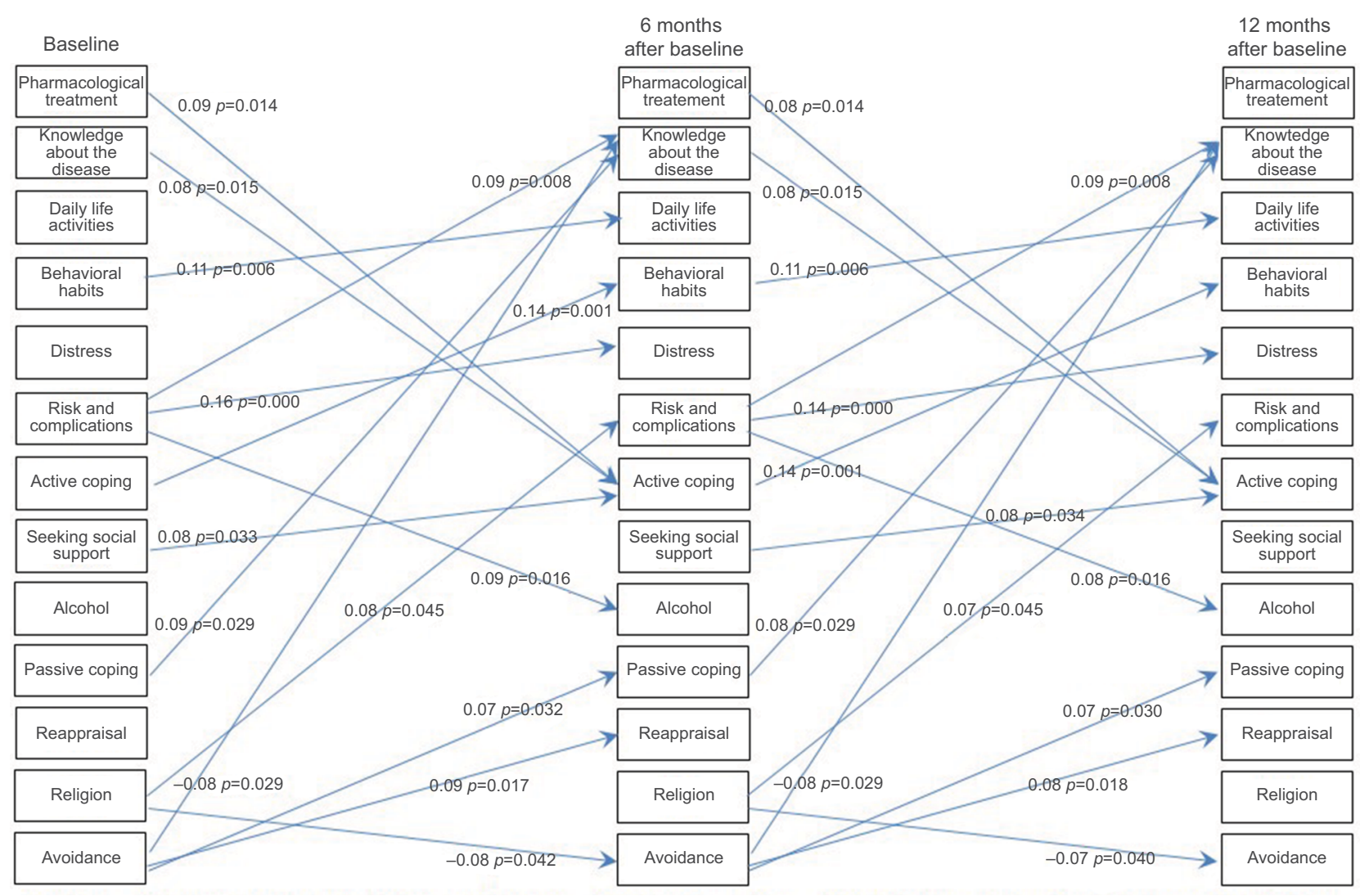

Figure 3 Final cross-lagged path model: the reciprocal effects model linking coping strategies and information needs.

Notes: Synchronous associations and stability coefficients are not presented for reasons of clarity; all significant cross-lagged coefficients are displayed. All path coefficients are standardized. 
focused coping, whereas older adults were more likely to use emotion-focused coping. ${ }^{50-52}$ Gender and education were related to religion and to the need for information on the pathology. Female and less educated patients reported searching for comfort in their religion and desiring more information on what hypertension is. Various studies have found a strong relationship between gender and religious coping, with women reporting greater use of religious coping methods. ${ }^{53,54}$ TCRi was negatively related to the need for information about behavioral habits. Patients with a higher risk of developing cardiac complications of hypertension desired less information on lifestyle. Some studies have noticed how health information provided in a stressful or unfamiliar situation is unlikely to be retained and can overwhelm even patients with advanced literacy skills. ${ }^{55}$ It is possible that patients with higher risk perceive their situation as more stressful compared to patients with lower risk and consider health information as something tedious that increases their stress. Surprisingly, no significant correlations arose between the need for information or coping strategies and the variable related to "Time since the diagnosis of hypertension." It was thought that patients who were newly diagnosed with the disease needed a greater amount of information compared with patients with a long history of disease (who had had more clinical evaluations where they might have been informed about their condition and had more time to search for additional information). In order to try to explain this result, it must be noted that patients were extremely heterogeneous for the variable "Time since the diagnosis of hypertension," as its value ranged from $<2$ months to $>30$ years. It is possible that a greater homogeneity in population study would lead to different results.

The hypothesis predicted that the relationships between coping strategies and information needs in hypertensive patients would be bi-directional, with both the variables influencing each other over time. The first hypothesis assumed that patients' coping strategies were related to their need for health information. It was expected that problem-focused strategies would be related to a greater need for information on how to manage hypertension, while emotion-focused strategies would be related to a lower need for health information. The main finding of the study sustained this hypothesis. In particular, active coping was related to a greater need for information regarding behavioral habits, which should be modified after a diagnosis of hypertension. Hence, patients who reported a greater need for information over time about diet, physical activity, drinking, and tobacco use were those with more active coping strategies, those who sought more instrumental and emotional support from others, and those who focused on the state of their illness, thus suppressing competing activities. These patients may have a deeper understanding of their situation and a greater awareness of what they can do to prevent their health status worsening. Avoidance coping was negatively related to the need for information regarding daily life activities. Hence, patients who tended to ignore it demonstrated less interest over time in information about daily habits that could be continued or should be changed due to the diagnosis of hypertension (eg, work, free time, and sexual activity). Such patients may underestimate hypertension and therefore perceive it as a minor problem that does not affect their lives. Consequently, they do not perceive this chronic disease as something that can have repercussions on their work or free time. Multiple reasons may explain these two findings. On the one hand, coping strategies may influence the way in which patients perceive the role and importance of the information provided by health care practitioners. For example, a patient who takes steps to make the situation better during stressful times may go to a medical examination with greater interest in obtaining information and with more positive expectations regarding the relationship with the physician and other health care providers. Such a patient may be more inclined to accept the information provided in a more positive and beneficial way by using it to better adapt to the disease. This patient is probably also better able to ask relevant questions and understand the explanations, thereby obtaining more personalized treatment from the physician. In addition, patients who are able to focus their attention on their disease, even when suppressing competing activities, may be more likely to put more effort into understanding their clinical status while also searching for additional information.

Conversely, patients who tend to ignore their illness and avoid focusing on it may go less frequently for medical examinations and visit their physicians only to obtain drug prescriptions. These patients rarely engage in meaningful conversations about their disease with health professionals and may perceive information as useless. Therefore, they do not actively search for additional advice or information, nor do they ask for explanations in the event they do not fully understand the information and explanations they were given. These patients may also avoid informing other people (relatives and friends) about their chronic condition, thereby limiting their opportunity to obtain further support and information. Differently from the initial hypothesis, passive coping was positively related to a greater need for information on how to change daily life activities after a diagnosis of hypertension. This result is contradictory; a 
negative relationship or no relationship was expected between this strategy and the need for information. This greater desire for information over time could indicate patients' attempts to learn how to deal with hypertension: passive coping arises, in fact, when people give up coping with a stressful situation because they believe they are not able to handle it. Perhaps, patients in this study believed that their inability to manage hypertension arose from a lack of knowledge and, consequently, they indicated that they needed more information in order to develop a deeper understanding of their illness to facilitate coping and reduce unhealthy behaviors. Future studies should try to further explore this unexpected result.

Generally, these results are in line with the idea that psychological factors closely related to individual health behaviors are associated with patients' information needs and can provide a better understanding of this topic than focusing only on sociodemographic characteristics. Studies on the relationships between psychological factors and needs for health information are still too limited, but the results reported here seem in line with the principal findings of two systematic reviews, which found that the main reason underlying patients' information needs was to collect information to better cope with the disease and the correlated stress. ${ }^{28,56}$ With respect to hypertension, very few studies have examined the role of coping strategies in the optimal management of this disease.$^{57}$ Few studies have analyzed the relations between coping strategies and clinical outcomes (eg, blood pressure levels), suggesting that avoidance, wishful thinking, and minimization of threat are related to higher diastolic blood pressure and an increased risk of hypertension. ${ }^{58,59}$ Other findings showed a relationship between lower blood pressure and the use of social support, being relaxed, taking positive time out, delegating or making positive reinterpretations. ${ }^{60}$ More empirical evidence is needed to better understand this.

The second hypothesis of this study assumed that health information needs were related to each patient's way to cope with the disease over time. In particular, it was expected that patients who are more interested in health information at baseline would adopt more problem-focused coping in the following months, while those who are less interested in information at baseline would adopt more emotion-focused coping findings confirmed this hypothesis. In particular, a greater need for information about the disease and the pharmacological treatment was related to a greater adoption of active coping strategies. Patients who wanted more information at baseline on how hypertension works in their bodies and the effects of the pharmacological treatment showed better coping over time. It is possible that these patients tried to bridge the gap between what they needed to know and what they actually knew by seeking more information on hypertension. The greater knowledge resulted in better coping strategies over the following months.

Additionally, the need for information on risk and complications was related to alcohol use. It is possible to argue that these patients try to manage the fear and stress related to their knowledge of the risks and complications of their disease by drinking. The more information they find on how their disease can worsen, the more they try to cope with the stress of this information with alcohol consumption. Nevertheless, this result should be further investigated for a better understanding.

Overall, the findings provide implications for putting interventions in place to improve patients' self-management skills and quality of life through the use of effective communication. As coping strategies could be modified through interventions, health care providers may consider measuring patients' strategies before the medical examination so they have time to refine the information they give to patients. Thus, health care providers could reduce patients' distress by incorporating techniques to help them develop their ability to cope with their chronic disease.

Current findings are unique in their focus on patients with hypertension. Previous research on the provision of appropriate health information focused mainly on patients with other illnesses where the disease is associated with acute symptoms. ${ }^{61-63}$ Although data of this nature are necessary to improve clinical practices, research should focus on patients with asymptomatic medical cases as well. In many respects, individuals with a diagnosis of hypertension are similar to people with no diagnosis. For example, people with hypertension usually do not experience any symptoms, and they continue their normal habits without improving their behavior, even when the long-term effects of this disease on health could be serious. Accordingly, focusing research and clinical efforts on high-risk patients, such as those with hypertension, is important for prevention. A second major strength of the study is its application of a three-wave longitudinal design that allows for examining how relationships among information needs and coping may change over time.

Despite its merits, the current study has certain limitations. The generalizability of the findings may be limited, considering that patients were recruited in a single health care center where they were already being treated for their disease. Furthermore, data from larger samples of patients are needed because the number of participants was not large enough to allow for the generalization of the findings. Moreover, attention to drop-out motivations could add 
knowledge in these fields. Additionally, the use of volunteer participants likely resulted in an overrepresentation of those who were more interested in the topics analyzed. Future research should consider randomly selected patients, and population-based surveys, to better explore and represent the aims and the population under investigation. In spite of these limitations, the present findings have the strength of providing initial evidence about the significant role that coping strategies have in information needs in patients with hypertension. Several avenues for future research are suggested. First, additional studies examining coping skills and strategies in patients with other chronic diseases are needed. Second, other variables could play a role in the relation between information needs and coping strategies. Here are two examples of elements that could have an effect on information needs: the amount of information participants already had when they were enrolled in the study and any information they acquired between the different time-points of the study.$^{64}$ If a domain is well known, there is no need for patients to gather other information or some new domains would arise if patients have sufficient knowledge about one domain; future investigation must consider the role of this variable in the relation between coping and information needs. Third, longitudinal data with more follow-ups are required to explore whether different coping strategies are predictive of the multiple information needs of patients as the disease progresses. Fourth, this research suggests that studies should examine whether 1) increasing assertive coping strategies, 2) decreasing reframing/avoidance coping, and 3) adapting health information to coping would increase patients' self-management of their condition, thus improving their health. It is important to understand whether the relationships that emerged between coping and the need for information have practical repercussions on patients' behaviors, especially with respect to lifestyle modification.

\section{Acknowledgment}

This work is supported by the Italian Ministry of Instruction, University and Research - FIRB "Futuro in ricerca" [grant number RBFR08YVUL].

\section{Author contributions}

All authors contributed toward data analysis, drafting and revising the paper, gave final approval of the version to be published, and agree to be accountable for all aspects of the work.

\section{Disclosure}

The authors report no conflicts of interest in this work.

\section{References}

1. Carlberg C, Ulven SM, Molnár F. Hypertension, atherosclerosis and dyslipidemias. In: Nutrigenomics. Springer; Cham, 2016:195-208.

2. Palagini L, Bruno RM, Gemignani A, Baglioni C, Ghiadoni L, Riemann D. Sleep loss and hypertension: a systematic review. Curr Pharm Des. 2013;19(13):2409-2419.

3. Heydari A, Ziaee ES, Gazrani A. Relationship between awareness of disease and adherence to therapeutic regimen among cardiac patients. Int J Community Based Nurs Midwifery. 2015;3(1):23-30.

4. van der Wal MH, Jaarsma T, Moser DK, Veeger NJ, van Gilst WH, van Veldhuisen DJ. Compliance in heart failure patients: the importance of knowledge and beliefs. Eur Heart J. 2006;27(4):434-440.

5. Schoenthaler A, Kalet A, Nicholson J, Lipkin M Jr. Does improving patient-practitioner communication improve clinical outcomes in patients with cardiovascular diseases? A systematic review of the evidence. Patient Educ Couns. 2014;96(1):3-12.

6. Dimatteo MR, Haskard-Zolnierek KB, Martin LR. Improving patient adherence: a three-factor model to guide practice. Health Psychol Rev. 2012;6(1):74-91.

7. Martin LR, Haskard-Zolnierek KB, DiMatteo MR. Health Behavior Change and Treatment Adherence: Evidence-Based Guidelines for Improving Healthcare. USA: Oxford University Press; 2010.

8. D'Addario M, Cappelletti E, Sarini M, et al. Communication and disease management: a qualitative study on coronary disease. Health Psychol Behav Med. 2015;3(1):94-108.

9. Hawkins RP, Kreuter M, Resnicow K, Fishbein M, Dijkstra A. Understanding tailoring in communicating about health. Health Educ Res. 2008;23(3):454-466.

10. Kreuter MW, Wray RJ. Tailored and targeted health communication: strategies for enhancing information relevance. Am J Health Behav. 2003;27(Suppl 3):S227-S232.

11. Bloom JR, Stewart SL, Johnston M, Banks P, Fobair P. Sources of support and the physical and mental well-being of young women with breast cancer. Soc Sci Med. 2001;53(11):1513-1524.

12. Ashton KC. Perceived learning needs of men and women after myocardial infarction. J Cardiovasc Nurs. 1997;12(1):93-100.

13. Astin F, Closs SJ, McLenachan J, Hunter S, Priestley C. The information needs of patients treated with primary angioplasty for heart attack: an exploratory study. Patient Educ Couns. 2008;73(2):325-332.

14. Czar ML, Engler MM. Perceived learning needs of patients with coronary artery disease using a questionnaire assessment tool. Heart Lung. 1997;26(2):109-117.

15. Decker C, Garavalia L, Chen C, et al. Acute myocardial infarction patients' information needs over the course of treatment and recovery. J Cardiovasc Nurs. 2007;22(6):459-465.

16. Timmins F. Commentary on Smith J \& Liles C (2007) Information needs before hospital discharge of myocardial infarction patients: a comparative, descriptive study. Journal of Clinical Nursing 16, 662-671. J Clin Nurs. 2008;17(11):1536-1538.

17. Greco A, Cappelletti ER, Monzani D, et al. A longitudinal study on the information needs and preferences of patients after an acute coronary syndrome. BMC Fam Pract. 2016;17:136.

18. Squiers L, Finney Rutten LJ, Treiman K, Bright MA, Hesse B. Cancer patients' information needs across the cancer care continuum: evidence from the cancer information service. JHealth Commun. 2005;10(Suppl 1): $15-34$.

19. Ormandy P. Defining information need in health - assimilating complex theories derived from information science. Health Expect. 2011;14(1):92-104.

20. Swenson SL, Buell S, Zettler P, White M, Ruston DC, Lo B. Patientcentered communication: do patients really prefer it? J Gen Intern Med. 2004;19(11):1069-1079. 
21. Folkman S, Moskowitz JT. Coping: pitfalls and promise. Annu Rev Psychol. 2004;55:745-774.

22. Monzani D, Steca P, Greco A, D'Addario M, Cappelletti E, Pancani L. The situational version of the brief COPE: Dimensionality and relationships with goal-related variables. Eur J Psychol. 2015;11(2):295-310.

23. Folkman S, Lazarus RS. An analysis of coping in a middle-aged community sample. J Health Soc Behav. 1980;21(3):219-239.

24. Lazarus RS, Folkman S. Stress, Appraisal, and Coping. New York: Springer Pub; 1984.

25. Daraz L, Macdermid JC, Wilkins S, Gibson J, Shaw L. The quality of websites addressing fibromyalgia: an assessment of quality and readability using standardised tools. BMJ Open. 2011;1(1):e00152.

26. Cline RJ, Haynes KM. Consumer health information seeking on the Internet: the state of the art. Health Educ Res. 2001;16(6):671-692.

27. Miller SM. Monitoring and blunting of threatening information: Cognitive interference and facilitation in the coping process. In: Sarason IG, Pierce GR, Sarason BR (editors). The LEA Series in Personality and Clinical Psychology. Cognitive Interference: Theories, Methods, and Findings. Hillsdale, NJ, USA: Lawrence Erlbaum Associates, Inc.; 1996:175-190.

28. Timmins F. Exploring the concept of 'information need'. Int $J$ Nurs Pract. 2006;12(6):375-381.

29. Gray RE, Fitch M, Greenberg M, Hampson A, Doherty M, Labrecque M. The information needs of well, longer-term survivors of breast cancer Patient Educ Couns. 1998;33(3):245-255.

30. Gray RE, Fitch M, Davis C, Phillips C. Interviews with men with prostate cancer about their self-help group experience. $J$ Palliat Care. 1997;13(1):15-21.

31. Mancia G, Fagard R, Narkiewicz K, et al; Task Force for the Management of Arterial Hypertension of the European Society of Hypertension and the European Society of Cardiology. 2013 ESH/ESC Practice Guidelines for the Management of Arterial Hypertension. Blood Press. 2014;23(1):3-16.

32. Norcini Pala A, Steca P. Illness perceptions and coping strategies among individuals diagnosed with HIV. J Behav Med. 2015;38(4):620-631.

33. Miyazaki Y, Bodenhorn N, Zalaquett C, Ng K. Factorial structure of brief cope for international students attending US colleges. Coll Stud J. 2008;42(3).

34. Hu Li-tze, Bentler PM. Cutoff criteria for fit indexes in covariance structure analysis: Conventional criteria versus new alternatives. Struct Equ Modeling. 1999;6(1):1-55.

35. Kenny D. Measuring model fit. Available from: http://davidakenny.net/ $\mathrm{cm} /$ fit.htm. Accessed September 13, 2018.

36. Muthén B, Muthén L. Mplus Version 7: User's Guide. Los Angeles, CA: Muthén \& Muthén; 2012.

37. Tabachnick B, Fidell L. Using Multivariate Statistics. New York: Harper Collins Publishers; 1989.

38. Matsuyama RK, Kuhn LA, Molisani A, Wilson-Genderson MC. Cancer patients' information needs the first nine months after diagnosis. Patient Educ Couns. 2013;90(1):96-102.

39. Scott JT, Thompson DR. Assessing the information needs of postmyocardial infarction patients: a systematic review. Patient Educ Couns. 2003;50(2):167-177.

40. Asendorpf JB, van Aken MA. Personality-relationship transaction in adolescence: core versus surface personality characteristics. $J$ Pers. 2003;71(4):629-666

41. Cole DA, Maxwell SE. Testing mediational models with longitudinal data: questions and tips in the use of structural equation modeling. J Abnorm Psychol. 2003;112(4):558-577.
42. Reichardt CS. The priority of just-identified, recursive models. Psychol Methods. 2002;7(3):307-315; discussion 323-337.

43. Bollen K. Structural Equations with Latent Variables. New York: John Wiley; 1989.

44. Kline RB. Principles and Practice of Structural Equation Modeling. 2nd ed. New York: Guilford Press; 2005.

45. Yuan K-H, Bentler PM. Three likelihood-based methods for mean and covariance structure analysis with nonnormal missing data. Sociological methodology. Sociol Methodol. 2000;30(1):165-200.

46. Satorra A. Scaled and Adjusted Restricted Tests in Multi-Sample Analysis of Moment Structures. Springer; Cham, 2000.

47. Satorra A, Bentler PM. A scaled difference chi-square test statistic for moment structure analysis. Psychometrika. 2001;66(4):507-514

48. Little RJA. A test of missing completely at random for multivariate data with missing values. JAm Stat Assoc. 1988;83(404):1198-1202.

49. Enders CK. Applied Missing Data Analysis. Guilford Publications; New York, NY, 2010.

50. Folkman S, Lazarus RS, Pimley S, Novacek J. Age differences in stress and coping processes. Psychol Aging. 1987;2171(2):171-184.

51. Folkman S, Lazarus RS. An analysis of coping in a middle-aged community sample. J Health Soc Behav. 1980;21(3):219-239.

52. Chen Y, Peng Y, Xu H, O'Brien WH. Age Differences in Stress and Coping: Problem-Focused Strategies Mediate the Relationship Between Age and Positive Affect. Int J Aging Hum Dev. 2018;86(4):347-363.

53. Gerber MM, Boals A, Schuettler D. The unique contributions of positive and negative religious coping to posttraumatic growth and PTSD. Psycholog Relig Spiritual. 2011;3(4):298-307.

54. Tarakeshwar N, Hansen N, Kochman A, Sikkema KJ. Gender, ethnicity and spiritual coping among bereaved HIV-positive individuals. Ment Health Relig Cult. 2005;8(2):109-125.

55. Zulick KM, Zulick PA, Rothrock JC. Patient Education and Health Literacy. Perioper Nurs Clin. 2009;4(2):131-139.

56. Rutten LJ, Arora NK, Bakos AD, Aziz N, Rowland J. Information needs and sources of information among cancer patients: a systematic review of research (1980-2003). Patient Educ Couns. 2005;57(3):250-261.

57. Rueda B, Pérez-García AM. Coping strategies, depressive symptoms and quality of life in hypertensive patients: mediational and prospective relations. Psychol Health. 2013;28(10):1152-1170.

58. Ariff F, Suthahar A, Ramli M. Coping styles and lifestyle factors among hypertensive and non-hypertensive subjects. Singapore Med J. 2011;52(1):29-34.

59. Wright TA, Sweeney D. Coping strategies and diastolic blood pressure. Psychol Rep. 1989;65(2):443-449.

60. Lindquist TL, Beilin LJ, Knuiman MW. Influence of lifestyle, coping, and job stress on blood pressure in men and women. Hypertension. 1997;29(1 Pt 1):1-7.

61. Booth K, Beaver K, Kitchener H, O’Neill J, Farrell C. Women's experiences of information, psychological distress and worry after treatment for gynaecological cancer. Patient Educ Couns. 2005;56(2):225-232.

62. Clark PA, Drain M, Gesell SB, Mylod DM, Kaldenberg DO, Hamilton J. Patient perceptions of quality in discharge instruction. Patient Educ Couns. 2005;59(1):56-68.

63. Osterberg L, Blaschke T. Adherence to medication. $N$ Engl J Med. 2005;353(5):487-497.

64. Coulter A, Parsons S, Askham J. Where are the patients in decisionmaking about their own care? World Health Organization; 2008. Available from: http://www.who.int/management/general/decisionmaking/WhereArePatientsinDecisionMaking.pdf. Accessed September 13, 2018. 


\section{Publish your work in this journal}

Psychology Research and Behavior Management is an international, peerreviewed, open access journal focusing on the science of psychology and its application in behavior management to develop improved outcomes in the clinical, educational, sports and business arenas. Specific topics covered in the journal include: Neuroscience, memory and decision making; Behavior modification and management; Clinical applications; Business and sports performance management; Social and developmental studies; Animal studies. The manuscript management system is completely online and includes a very quick and fair peer-review system, which is all easy to use. Visit http://www dovepress.com/testimonials.php to read real quotes from published authors.

Submit your manuscript here: https://www.dovepress.com/psychology-research-and-behavior-management-journal 